\section{Participants in pre-WHCLIS activities frame resolutions}

\author{
by Patricia A. Wand,
}

Chair, ACRL Task Force on WHCLIS

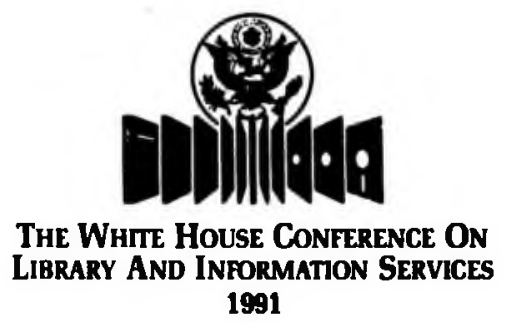

1991
Despite several unforeseen hitches on the national level and the inevitable politics that accompany a major undertaking of this nature, activities leading up to the White House Conference on Libraries and Information Service are on schedule and gaining momentum. The profession is abuzz and enthusiasm increases in quantum leaps with each pre-conference event.

To date, 30 states and territories have held preconference activities. Issues that need to be addressed on the national level are being received regularly in the WHCLIS Office as various states finalize their resolutions. Many states are compiling local agendas as well.

At the 1990 Virginia Governor's Conference, for example, the resolutions written on November 11 addressed numerous issues, including:

- the role of libraries in economic development and international relations,

- education for information professions,

- confidentiality and censorship,

- cultural diversity and populations with special needs,

- access to information including that generated by federal and state governments,

- developing an electronic network such as the proposed National Research and education Network (NREN),

- information literacy and life-long learning needs of citizens,

- measuring and promoting library services,

- preservation, and

- funding.

Delegates from Virginia who will attend the White House Conference in July, 1991, were chosen during the Governor's Conference and were directed to carry 16 of the 22 Virginia resolutions to the national conference.

Most pre-conference events are sponsored by states and territories who will send a designated number of delegates to the White House Conference. One group, however, was called together to focus on a single, overarching issue: networking.

The Library of Congress Network Advisory Committee invited over 60 representatives from various library and information profession associations to meet for two days in December to write resolutions and develop an action plan for the ' $90 \mathrm{~s}$ that addresses the interdependence of libraries and their need for connectivity. The "Networks for Networkers II" Conference emerged from the concern that electronic networking may be overshadowed in the White House Conference agenda by the myriad of other legitimate needs of libraries.

The Conference was coordinated by Henriette D. Avram and framed around background papers and discussion groups. Papers by Lewis Branscomb and Brian Kahin, Ken Dowlin, Peter Lyman, Clifford Lynch, Nina Matheson, Howard McGinn, Douglas Van Houweling, and Fred Weingarten were distributed before and presented for discussion during the conference.

Participants wrote seven resolutions emphasizing the need for the proposed National Research and Education Network (NREN) to include all types of libraries and be accessible in all socioeconomic populations. The resolutions also highlighted the leadership role that well-prepared information professionals must take in a democratic society where an informed citizenry is the linchpin. Libraries and information centers are urged to forge new partnerships with public and private service providers and users to meet the diverse needs of society.

These are but two examples of events happening across the country and in the territories to heighten awareness and prepare delegates who will meet July 9-13, 1991, in the Washington Convention Center for the second White House Conference on Libraries and Information Service. 